
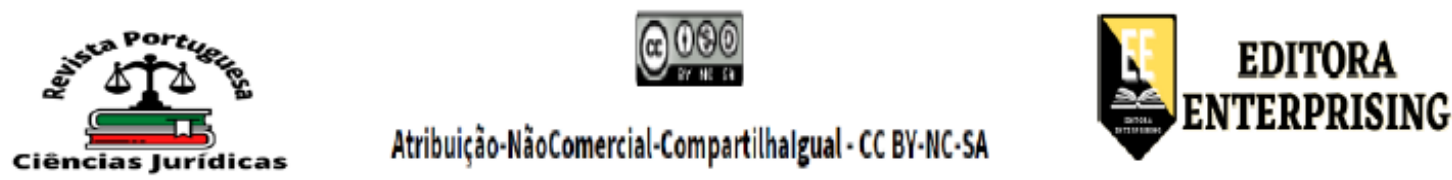

\title{
ASSÉDIO MORAL NAS ORGANIZAÇÕES EMRESARIAIS: UMA ABORDAGEM SOBRE AS RELAÇÕES ESTABELECIDAS NO AMBIENTE DE TRABALHO
}

\section{MORAL HARASSMENT IN BUSINESS ORGANIZATIONS: AN APPROACH ON THE RELATIONSHIPS ESTABLISHED IN THE WORKPLACE}

\author{
Marjory Andressa Ferreira Domingos ${ }^{1}$ \\ Lana Caroline Barbosa do Nascimento ${ }^{2}$ \\ Anderson Daniel da Silva Batista ${ }^{3}$ \\ Mario Teixeira de Mendonça Neto ${ }^{4}$ \\ Dr. Robson Antonio Tavares Costa ${ }^{5}$
}

\section{RESUMO}

Este artigo propõe uma análise sobre a ocorrência do assédio moral nas organizações empresariais, fazendo uma abordagem sobre as relações de trabalho estabelecidas entre os individuos, expondo os cenários que possibilitam a sua prática e os principais fatores que norteiam esse tipo de assédio, tais como a competitividade excessiva, dando enfoque, sobretudo aos prejuízos causados por ele. A partir das informações adquiridas durante a pesquisa, foi possível constatar que o assédio moral constitui-se como uma forma eficaz de causar danos psicológicos as suas vitimas, constituída em uma prática extremamente nociva ao clima organizacional.

Palavras-chave: assédio moral, relações de trabalho, competitividade, ambiente organizacional.

\section{ABSTRACT}

This article proposes an analysis of the occurrence of bullying in business organizations, approaching the work relationships established between individuals, exposing the scenarios that enable its practice and the main factors that guide this type of harassment, such as

\footnotetext{
${ }^{1}$ Universidade Federal do Amapá-UNIFAP- E-mail: marjorydomingos@ hotmail.com

${ }^{2}$ Universidade Federal do Amapá-UNIFAP- E-mail: lananascimento15@gmail.com

${ }^{3}$ Universidade Federal do Amapá-UNIFAP- E-mail: andersondanielbatista@ hotmail.com

${ }^{4}$ Universidade Federal do Amapá-UNIFAP- E-mail: mariomac@unifap.br/

${ }^{5}$ Universidade Federal do Amapá-UNIFAP- E-mail: ratcosta@gmail.com

Domingos, M.A.F., Nascimentos, L.C.B., Batista, A.D.S., Mendonça, M.N., Costa, R.A.T; Assédio Moral Nas Organizações Empresariais: Uma Abordagem Sobre As Relações Estabelecidas No Ambiente De Trabalho. Revista Portuguesa de Ciências Jurídicas V.1, No2, p.66-74, Ago/Dez. 2020. Artigo recebido em 25/11/2020. Última versão recebida em 11/12/2020. Aprovado em 20/12/2020.
} 
Assédio Moral Nas Organizações Empresariais: Uma Abordagem Sobre As Relações Estabelecidas No Ambiente De Trabalho

excessive competitiveness, focusing, above all, on the damage caused by it. From the information acquired during the research, it was possible to verify that bullying is an effective way to cause psychological damage to its victims, constituted in an extremely harmful practice to the organizational climate.

Keywords: bullying, labor relations, competitiveness, organizational environment.

\section{INTRODUÇÃO}

O assédio moral, caracterizado por exercer danos psicológicos aos individuos, é considerado um problema organizacional, cuja prática implica em graves consequências para as suas vitimas, fazendo com que elas fiquem desestabilizadas, e, ocasionalmente, afastem-se do ambiente de trabalho. Na maioria dos casos, suas consequências não se restringem às horas de expediente, podendo atingir a vida pessoal dos indivíduos. Mediante a isso, este trabalho se justifica pelo interesse de investigar os fatores que norteiam o Assédio Moral, tendo em vista uma futura contribuição para a análise dos problemas a ele relacionados.

Em um primeiro momento, serão trabalhados os fatores relacionados à esfera do trabalho. Em seguida, será tratada a problemática do Assédio Moral, dos ambientes considerados propícios para a sua ocorrência, bem como, dos individuos envolvidos. E por último, serão trabalhadas as propostas que objetivem reduzir e ou eliminar a prática e os efeitos causados pelo problema em questão.

\section{O trabalho e a competitividade excessiva}

O trabalho, em sua essência, possibilita o reconhecimento social do homem; gera riquezas e status (em casos específicos). Certamente, por tais razões, o homem procura se firmar profissionalmente, e vem, a cada dia, investindo mais na sua capacitação, sobretudo, porque o mercado encontra-se extremamente seletivo. Há uma competição excessiva e a maioria das pessoas deseja ascensão profissional. A competitividade (enquanto fator natural) é considerada intrínseca ao mercado de trabalho e leva-o a exigir profissionais mais eficientes. Porém, “ [...] num ambiente em que aparentemente vale tudo, como no competitivo mundo 
Assédio Moral Nas Organizações Empresariais: Uma Abordagem Sobre As Relações Estabelecidas No Ambiente De Trabalho

empresarial, as considerações éticas são as primeiras a perder o valor" (ALENCASTRO, 2010, p. 21).

Filho e Siqueira (2008) afirmam que a supervalorização competição do processo produtivo impossibilita a comunicação. Segundo eles, essa organização favorece o desenvolvimento do comportamento agressivo, pois de um lado estabelece-se a necessidade de ser competitivo, capaz, qualificado e criativo. De outro, o trabalhador sabe que se não estiver preparado para a nova realidade, isto pode significar a perda do emprego.

Para Freitas (2007), as próprias organizações definem quais padrões de relacionamentos irão existir entre os seus funcionários; elas também constroem o ambiente e as condições nas quais o trabalho será realizado, além de direcionar autoridade e responsabilidade aos individuos.

\section{O Assédio Moral}

Freitas (2007) conceitua o assédio moral como uma conduta intencional, frequente e repetida, que visa humilhar, constranger e desqualificar um indivíduo ou grupo, no ambiente de trabalho, rebaixando suas condições de trabalho, atingindo a sua dignidade e comprometendo a integridade de sua vida profissional e pessoal.

Filho e Siqueira (2007) afirmam que este fenômeno, a partir da década de 1990, passou a ser identificado como fator destrutivo do clima organizacional, não somente pela redução da produtividade dos funcionários, mas, sobretudo pelos danos psicológicos envolvidos na sua conjuntura. Na visão de Alencastro (2010), este tipo de assédio pode ser caracterizado como uma exposição frequente do funcionário a ocasiões humilhantes no trabalho. $O$ autor também nos fornece exemplos de como pode se constituir essa conduta no ambiente empresarial:

[...] advertências feitas de forma humilhante e na frente dos outros empregados, preconceitos, autoritarismo exagerado por parte das chefias, isolamento e segregação, demissão desrespeitosas (por telefone, e-mail etc.), insultos e grosserias de superiores" (ALENCASTRO, 2010, p. 92). 
Assédio Moral Nas Organizações Empresariais: Uma Abordagem Sobre As Relações Estabelecidas No Ambiente De Trabalho

Filho e Siqueira (2010) ainda complementam que para desestabilizar um funcionário, basta colocar seus erros em evidência, oferecer-lhes tarefas muito difíceis de realizar ou então, tarefas que sejam inúteis para o desenvolvimento da empresa. Afirmam ainda que, o ato de não oferecer ao indivíduo os meios para ele trabalhar é uma forma de transmitir à pessoa, a ideia de que ela é incompetente, ou de que não é útil para a organização.

\title{
2.1 O ambiente propício ao Assédio Moral
}

Freitas (2007) nos diz que, ao considerar o assédio moral como um problema organizacional, pode-se afirmar que algumas instituições deixam de cuidar de determinados aspectos que favorecem a ocorrência desse fenômeno. Dessa forma, o assédio moral ocorre, porque existem ambientes que permitem e ou mascaram a sua existência, sobretudo, por não receberem atenção adequada a por parte dos gestores. A autora acrescenta que a excessiva valorização das hierarquias, amedronta os funcionários e transmite a ideia de que o chefe é um ser inquestionável, causando falhas no processo democrático da empresa:

\begin{abstract}
Analisando as organizações como palcos de interpretações e de ações de indivíduos e grupos, verificamos que algumas condições facilitam a emergência de comportamentos violentos, abusivos e humilhantes. Ambientes em que vigoram uma cultura e um clima organizacionais permissivos tornam o relacionamento entre os indivíduos desrespeitoso e estimulam a complacência e a conivência com o erro, o insulto e o abuso intencionais. [...] a supervalorização de hierarquias, em que os chefes são seres intocáveis e inquestionáveis, torna o comportamento decente e democrático uma falha ou uma debilidade [...] (FREITAS, 2007, p. 04)
\end{abstract}

Filho e Siqueira (2007) confirmam que esse tipo de cenário é propício para o surgimento da violência no trabalho; não a física, mas sim a violência psicológica, que quando empregada de forma repetitiva pode ser configurada como assédio moral. Freitas (2001) contribui nos dizendo que é intrínseca as organizações a busca pelo controle do comportamento dos funcionários e das condições internas, e, que este fator pode dificultar as interações entre os individuos. A autora, também nos diz que algumas empresas, são totalmente negligentes, no que diz respeito aos direitos do funcionário. 
Assédio Moral Nas Organizações Empresariais: Uma Abordagem Sobre As Relações Estabelecidas No Ambiente De Trabalho

\subsection{As vítimas e as consequências do Assédio Moral}

Sob os pontos de vista de Caniato e Lima (2008), as pessoas mais visadas para se tornarem vítimas do assédio moral são aquelas que costumam apresentar algum tipo de oposição as autoridades; ou indivíduos que possuem mais de cinquenta anos, precipitadamente avaliados como menos produtivos. As mulheres também são assediadas, porém, de forma diferente dos homens, pois as ações contra elas podem ter um significado machista. $\mathrm{O}$ assédio, em muitas ocasiões está diretamente relacionado a todo e qualquer tipo de discriminação, seja ela racial, religiosa, ou até mesmo em função da sexualidade. Vale ressaltar que o assédio moral também pode estar ligado a uma questão pessoal, na qual o agressor revela uma aversão à vítima, maltratando-a, com a intenção de fazê-la sair do emprego. As autoras também nos dizem que as agressões podem ocorrer de maneira horizontal, ou seja, entre colegas, ou de forma vertical, quando ocorre entre superior e subordinado. Freitas (2007) revela outras possíveis razões que podem levar ao assédio:

\footnotetext{
Reestruturações feitas sem planejamento em relação às pessoas e cargos afetados, sem transparência e sem critérios claros de avaliação e negociação de demissões, geram rancores, revanches, ressentimentos e lutos. O mesmo pode ser dito em relação aos casos de fusões, aquisições e parcerias em que algumas funções executivas e de coordenação podem ser duplicadas e nas quais não foram negociadas as saídas, as transferências ou as reconversões desses profissionais. Terceirizações podem gerar conflitos entre os funcionários efetivos e os prestadores de serviços, criando um ambiente de primeira e segunda classes para algumas categorias, o que estimula humilhações e exclusões; serviços com alto grau de rotina [...] (FREITAS 2007, p. 5)
}

Freitas (2007) explica que o assédio moral além de causar danos individuais, também afeta o conjunto empresarial. Na esfera individual, a pessoa tem a identidade e a autoestima atingidas; ocorrem desordens de natureza psíquica, familiar, social e profissional. No campo organizacional, é comum acontecerem afastamentos por motivos de saúde e acidentes no trabalho, o que eleva o processo rotatividade de funcionários, gerando despesas extras para a empresa. Há também, uma quebra tanto do clima organizacional quanto das relações interpessoais, o que 
Assédio Moral Nas Organizações Empresariais: Uma Abordagem Sobre As Relações Estabelecidas No Ambiente De Trabalho

pode ocasionar um descompasso nas atividades e a exposição negativa da empresa perante os clientes.

\subsection{Medidas preventivas}

Para Souto (2009), analisar a subjetividade no trabalho, possibilita a abertura para novos questionamentos que indicam a necessidade de estudos que criem maiores informações sobre a experiência do trabalhador e o ambiente que o cerca. Tendo em vista que a liderança exerce um papel fundamental para a percepção do sujeito acerca do trabalho, torna-se extremamente necessário o estudo da gestão de pessoas na atualidade, bem como, identificar as tendências relacionadas a ela.

Alencastro (2010) nos diz que a empresas devem adotar políticas bem definidas no que diz respeito à integridade dos funcionários. A conscientização dos gestores sobre o problema em questão é fundamental para que haja uma redução das agressões, e, para isto é necessária a presença de uma liderança eficaz. Além disso, também é importante que esse processo de conscientização atinja a todos os setores da empresa. Filho e Siqueira complementam que:

As organizações, por meio das áreas de gestão de pessoas, precisam tornar publico o problema e investir pesadamente na formação de seus gestores, inserindo, cada vez mais, temas relacionados a gestão de pessoas em suas grades de treinamento. As organizações precisam se preocupar mais com os individuos do que com os números e impedir a ação de gestores perversos ou paranoicos, adotando medidas para obriga-los a controlar seu comportamento (FILHO; SIQUEIRA 2010, p.14).

\section{CONSIDERAÇÕES FINAIS}

O assédio moral no ambiente organizacional corresponde a um fenômeno profissional assinalado pela desumanização (intencional, sistematizada e repetitiva) das relações de trabalho estabelecidas entre os diferentes níveis de uma empresa. Compreende-se que a sua prática agride e gera prejuízos para a própria organização, para a sociedade, mas principalmente, para quem é vítima.

O presente artigo teve como perspectiva propagar conhecimentos sobre 0 assédio moral, atendo-se ao fato de que este viola direitos fundamentais como a RPCJ, Portugal-PT, V.1, N², p. 66-74, Ago./Dez.2020 www.revistas.editoraenterprising.net Página 71 
Assédio Moral Nas Organizações Empresariais: Uma Abordagem Sobre As Relações Estabelecidas No Ambiente De Trabalho

dignidade da pessoa humana; além de afetar o clima organizacional - fundamental para o bom desempenho das atividades.

Dessa forma, analisar os problemas que envolvem as organizações é de grande relevância para estabelecer condutas que visem melhorar a relação entre os funcionários e, neste caso, que o trabalho de prevenção e de redução da ocorrência do assédio moral é indispensável na conquista de um ambiente de trabalho saudável e produtivo. Compreendendo que o bom funcionamento das empresas não pode ser visto unicamente pelos resultados econômicos, mas também por seu âmbito profissional, por questões ligadas ao corpo de colaboradores.

Para minimizar a ocorrência do assédio moral no ambiente de trabalho, antes de tudo, faz-se necessário estudar e conhecer as suas causas e, posteriormente, suas características. Além disso, é importante que sejam realizadas mudanças comportamentais de estilos de liderança e humanização nas relações de trabalho.

\section{REFERÊNCIAS BIBLIOGRÁFICAS}

ALENCASTRO, Mario Sergio Cunha. Ética empresarial na prática: liderança, gestão e responsabilidade corporativa. Curitiba: Ibepex, 2010.

CANIATO, Ângela Maria Pires; LIMA, Eliane da Costa. Assédio moral nas organizações de trabalho: perversão e sofrimento. Cadernos de Psicologia Social do Trabalho versão impressa ISSN 1516-3717 Cad. psicol. soc. trab. v.11 n.2 São Paulo dez. 2008

Disponível em: <http://pepsic.bvsalud.org/scielo. php?pid=S1516-

37172008000200004\&script=sci_arttext>. Acesso em: 26 de maio de 2014

CARAN, Vania Claudia Spoti. et al. Assédio moral entre docentes de instituição pública de ensino superior do Brasil. Acta Paulista de Enfermagem. vol.23 no.6 São Paulo 2010. 
Assédio Moral Nas Organizações Empresariais: Uma Abordagem Sobre As Relações Estabelecidas No Ambiente De Trabalho

Disponível em:

<http://www.scielo.br/scielo.php?script=sci_arttext\&pid=S010321002010000600004> . Acesso em: 26 de maio de 2014.

FILHO, Antonio Martinigo; SIQUEIRA, Marcus Vinicius Soares. Assédio Moral e Gestão de Pessoas: Uma Análise do Assédio Moral nas Organizações e o Papel da Área de Gestão de pessoas. RAM. Revista de Administração Mackenzie, vol 9, n 5. São Paulo, 2008.

Disponível em:

<http://www.scielo.br/scielo.php?pid=S167869712008000500002\&script=sci_arttext> . Acesso em 26 de maio de 2014

FREITAS, Maria Ester de. Quem paga a conta do assédio moral no trabalho? RAE-eletrônica, vol. 6, núm. 1. Escola de Administração de Empresas de São Paulo. Brasil, 2007.

Disponível em: < http://www.redalyc.org/pdf/2051/205114655011.pdf>. Acesso em 26 de maio de 2014.

Assédio moral e sexual: Faces do poder perverso nas organizações. RAE- Revista de Administração de empresas. Vol 41. São Paulo, 2001 Disponível em: <HTTP.www.scielo.brpdfraev41n2v41n2a02.pdf> Acesso em 26 de maio de 2014

HIRIGOYEN, Marie-France. Mal-estar no trabalho, redefinindo o assédio moral. Rio de Janeiro: Bertrand do Brasil, 2002.

SOUTO, Karine Gomes dos Santos. Assédio moral no trabalho, práticas e consequências: um estudo de caso nas empresas do ramo de confecções associadas à câmara de dirigentes lojistas de montes claros. Montes Claros, 2009, 85p. (Monografia apresentada à Faculdade de Ciências Sociais Aplicadas da Faculdade Santo Agostinho, para obtenção do título de Bacharel em Administração). 
Assédio Moral Nas Organizações Empresariais: Uma Abordagem Sobre As Relações Estabelecidas No Ambiente De Trabalho

Disponível em:

$<$ http://www.fucape.br/premio_excelencia_academica/upld/trab/1/karine.pdf>. Acesso em 26 de maio de 2014 